\title{
Population structure and demographic inferences concerning the endangered onychophoran species Epiperipatus acacioi (Onychophora: Peripatidae)
}

\author{
G.A. Lacorte ${ }^{1}$ I.S. Oliveira ${ }^{2,3}$ and C.G. Fonseca ${ }^{1}$ \\ 'Departamento de Biologia Geral, Instituto de Ciências Biológicas, \\ Universidade Federal de Minas Gerais, Belo Horizonte, MG, Brasil \\ ${ }^{2}$ Departamento de Zoologia, Instituto de Ciências Biológicas, \\ Universidade Federal de Minas Gerais, Belo Horizonte, MG, Brasil \\ ${ }^{3}$ Institute of Biology II: Molecular Evolution \& Animal Systematics, \\ University of Leipzig, Leipzig, Germany \\ Corresponding author: G.A. Lacorte \\ E-mail: gustavo.lacorte@gmail.com
}

Genet. Mol. Res. 10 (4): 2775-2785 (2011)

Received December 6, 2010

Accepted July 30, 2011

Published November 9, 2011

DOI http://dx.doi.org/10.4238/2011.November.9.1

\begin{abstract}
Epiperipatus acacioi (Onychophora: Peripatidae) is an endemic species of the Atlantic rainforest in southeastern Brazil, with a restricted known distribution, found only in two nearby areas (Tripuí and Itacolomi). Mitochondrial gene COI sequences of 93 specimens collected across the known range of E. acacioi were used to assess the extant genetic diversity and patterns of genetic structure, as well as to infer the demographic history of this species. We found considerable variability within the populations, even though there has been recent environmental disturbance in these habitats. The samples from the two areas where this species is found showed significantly different $\mathrm{COI}$ sequences and constitute two distinct populations [exact test of sample differentiation $(\mathrm{P}=0.0008)$ and pairwise $F_{\mathrm{ST}}$ analyses $\left.\left(F_{\mathrm{ST}}=0.214, \mathrm{P}<0.00001\right)\right]$. However, there was little genetic differentiation among samples from different sampling sites within populations, suggesting that the potential for dispersal of E. acacioi is
\end{abstract}


greater than would have been expected, based on their cryptic behavior and reduced vagility. Mismatch analyses and neutrality tests revealed evidence of recent population expansion processes for both populations, possibly related to variations in the past distribution of this species.

Key words: Onychophora; Mitochondrial DNA; Dispersal; Population expansion; Population structure

\section{INTRODUCTION}

Habitat fragmentation is considered to be a major threat to many species, because the isolation of small populations can lead to the loss of genetic variants. Species with limited dispersal ability are more susceptible to habitat fragmentation, which can lead to a remarkable genetic divergence between populations (Conner and Hartl, 2004). Furthermore, in isolated populations with small population sizes, there is a rising risk that genetic drift will lead to a reduction of genetic diversity (Reed and Frankham, 2003). Another factor influencing gene flow within and among animal populations is vagility. Species with low vagility are expected to have low levels of gene flow and high levels of population differentiation, and they are more sensitive to habitat loss or degradation (Bohonak, 1999; Anderson, 2007).

The Phylum Onychophora, whose members are commonly known as "velvet worms" or "peripatus", comprises a group of terrestrial invertebrates that has recently received broad attention among evolutionary biologists, because of the controversy about their evolutionary relationships with other animal phyla (Boore et al., 1995; Braband et al., 2010a,b). Onychophorans show cryptic behavior, low vagility and high sensitivity to desiccation and to temperature oscillation (Lavallard and Campiglia, 1975a). They are confined to moist microhabitats, including ground galleries, decomposing logs and leaf litter (Monge-Nájera, 1995). In addition, onychophoran species are morphologically conservative, showing high levels of endemism and cryptic speciation (Tait and Briscoe, 1995). Because of all these factors, the onychophoran populations are susceptible to habitat disturbance and all onychophoran species were mentioned as "vulnerable" by the IUCN (Wells et al., 1983; New, 1995).

Epiperipatus acacioi (Marcus and Marcus, 1955) is the most studied species of Onychophora in South America, particularly from a physiological and reproductive standpoint (Campiglia and Lavallard, 1973; Lavallard and Campliglia, 1973, 1975a,b). E. acacioi individuals are gregarious and are usually found in small groups inhabiting natural galleries in the ground or in shaded ravines during the wet season. In the dry season, specimens of $E$. acacioi occur deeper in the ground galleries (Oliveira et al., 2010). E. acacioi is viviparous, females are fertilized only once through the vagina when they are 5 to 9 months old. Sperm is stored in spermathecae and they give birth when they reach the age of 15 to 23 months. On average, each female gives birth to one individual a year and each female can produce up to 8 individuals (Lavallard and Campiglia, 1975a). The lifetime observed in captivity was three and half years for males and six years for females (Lavallard and Campiglia, 1975b). These aspects of E. acacioi biology suggest that the biotic potential is significantly smaller than most terrestrial invertebrates, and that the populations are maintained with small sizes.

Epiperipatus acacioi is endemic to the Atlantic rainforest of southeastern Brazil, with its distribution restricted to two locations: the areas of the Tripuí Ecological Station (type-locality, 3.5 
$\mathrm{km}^{2}$ ) and Itacolomi State Park (near the type-locality, $75 \mathrm{~km}^{2}$ ), both in the municipality of Ouro Preto. This area has suffered anthropogenic pressure since the end of seventeenth century when mining activities were established (Pedralli et al., 1997), and more recently, due to the expansion of the Ouro Preto urban area and the construction of railways and roads with varying levels of traffic. Both the restricted distribution of E. acacioi and the high human pressure on its habitat are a threat to their populations and justify conservation efforts. Currently, E. acacioi is the only onychophoran species in Brazil recorded in the Official List of Threatened Species (Ibama, 1522/89). Furthermore, this species was the first invertebrate species in Brazil used as a flagship for the creation of a conservation unit (i.e., the Tripuí Ecological StationTripuí) (Lewinsohn et al., 2005).

Although the areas of occurrence of E. acacioi are currently protected, they suffered environmental changes in the previous decades such as deforestation, establishment of human settlements and construction of roads and railways. All these factors associated with biological aspects of the species may have caused effects in the populations of E. acacioi. In this study, we used cytochrome oxidase I mitochondrial sequences of $E$. acacioi populations to detect the genetic structure of the species, to infer its demographic history and to provide information for the conservation and management of this endangered invertebrate species.

\section{MATERIAL AND METHODS}

\section{Sampling}

DNA samples from 93 specimens collected across the known range of $E$. acacioi were used in this study (Figure 1). Samples from the Tripuí Ecological Station were obtained from collections made in 2000 at eight occurrence sites (designated in this study as sampling sites T1 to T8). Samples from Itacolomi State Park were obtained from collections made in 2007 at two sites (sampling sites I1 and I2). Geographical coordinates of each occurrence site were recorded by a GPS device (Table 1).

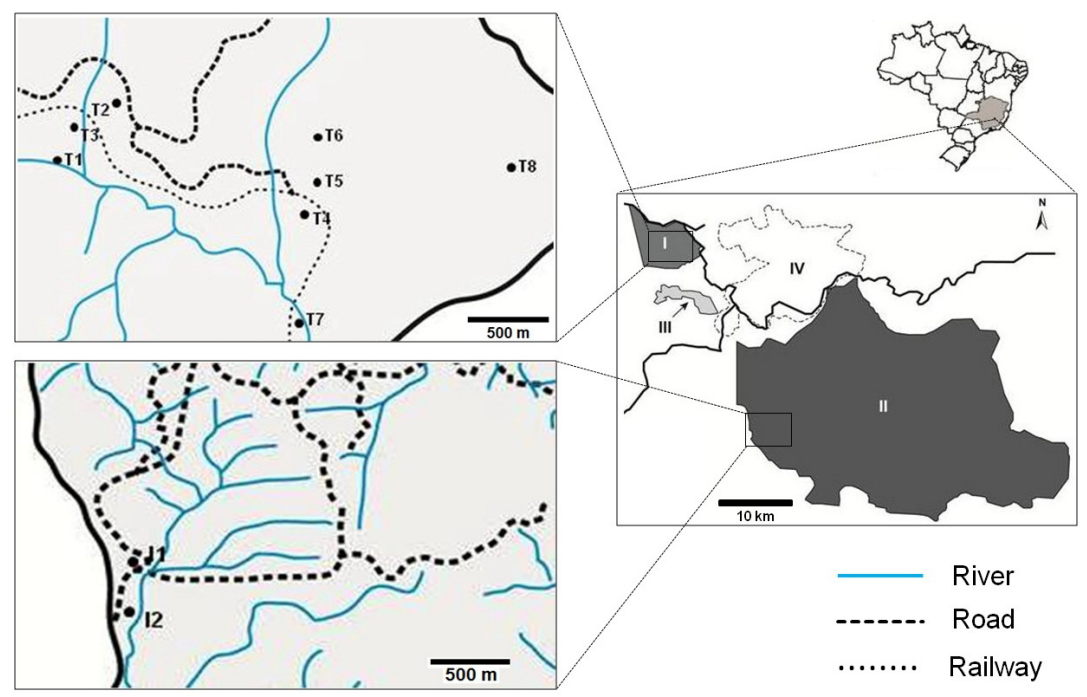

Figure 1. Map showing the occurrence area of Epiperipatus acacioi and sampling sites. I = Tripuí Ecological StationTripuí; II = Itacolomi State Park; III = Mining area; IV = Ouro Preto urban area. 


\section{Laboratory protocol}

Two lobopods (legs) from each specimen were used for DNA isolation using the Wizard $^{\circledR}$ Genomic DNA Purification Kit (Promega, Madison, WI, USA) according to the manufacturer protocol. DNA sequences of the mitochondrial cytochrome oxidase I gene (COI) were amplified using the primers COI5584 (5'-TGTGACTGGTCATGCATTGT-3') and COI6174 (5'-GAAACTATTCCAAAGCCAGGAA-3'). PCR amplifications were performed in $20 \mu \mathrm{L}$ containing $40 \mathrm{ng}$ genomic DNA, Buffer 1B (Phoneutria ${ }^{\circledR}$, Belo Horizonte, MG, Brazil; $1.5 \mathrm{mM} \mathrm{MgCl} 2,10 \mathrm{mM}$ Tris-HCl, $50 \mathrm{mM} \mathrm{KCl}, 0.1 \%$ Triton X-100), 0.8 $\mu \mathrm{M}$ dNTPs, $0.3 \mu \mathrm{M}$ primers, $1 \%$ bovine serum albumin (BSA) and $1 \mathrm{U}$ Taq polymerase (Phoneutria ${ }^{\circledR}$ ). After an initial denaturing step for $5 \mathrm{~min}$ at $94^{\circ} \mathrm{C}$, the PCR conditions for the $C O I$ fragments followed a standard three-step protocol, with 27 cycles of 1) denaturing for $45 \mathrm{~s}$ at $94^{\circ} \mathrm{C}, 2$ ) annealing for $45 \mathrm{~s}$ at $56^{\circ} \mathrm{C}$, and 3) extension for $1 \mathrm{~min}$ at $72^{\circ} \mathrm{C}$, followed by a final extension step for $5 \mathrm{~min}$ at $72^{\circ} \mathrm{C}$. The PCR products were purified using a solution of $20 \%$ polyethylene-glycol (PEG 8000 ) and $2.5 \mathrm{M} \mathrm{NaCl}$ according to Sambrook and Russell, (2001). After purification, the PCR products were sequenced in both directions using the PCR primers, BigDye Terminator Kit v3 (Applied Biosystems, Foster City, CA, USA) and an $\mathrm{ABI} 3100^{\circledR}$ automated sequencer (Applied Biosystems). The sequences were assembled and checked for quality using Phred v.0.20425 (Ewing et al., 1998; Ewing and Green, 1998) and Phrap v.0.990319 softwares (Green, 1994) and the assembled chromatograms were verified and edited using Consed 12.0 (Gordon et al., 1998). The sequences obtained were aligned using the Clustal $\mathrm{W}$ algorithm implemented in MEGA4.1 (Tamura et al., 2007). The sequences were deposited in GenBank (accession Nos. HQ655588-HQ655680).

\section{Data analyses}

We evaluated genetic diversity by means of a number of polymorphic sites and haplotypes, and estimates of haplotypic and nucleotide diversities, obtained with DNAsp v.5 (Librado and Rozas, 2009). An exact test (Raymond and Rousset, 1995) was applied to verify the differentiation between Tripuí and Itacolomi populations. To detect population genetic structure, we performed the analysis of molecular variance (AMOVA). Levels of genetic divergence between samples from each sampling site within Tripuí and Itacolomi locations were estimated with the fixation index $F_{\mathrm{ST}}$ and their significance for population comparisons was assessed using 10,000 permutations. Pairwise $F_{\mathrm{ST}}$ values were used to estimate the average gene flow per generation $(\mathrm{Nm})$ between the sites, applying the equilibrium relationship for haploid data: $F_{\mathrm{ST}}=1 /(2 \mathrm{Nm}$ $+1)$. The exact test, AMOVA, $F_{\mathrm{ST}}$ values, and permutations were calculated using ARLEQUIN v3.1 (Schneider et al., 2000). Correlation between genetic (pairwise $F_{\mathrm{ST}}$ ) and geographical distances ( $L n$ of geographical distances) was tested with a Mantel nonparametric permutation test with 1000 replications, implemented in the AIS software (Miller, 2005).

Mismatch distribution analysis of COI sequences was performed to infer recent population expansions (uni-modal distribution), allopatric divergence followed by population growth (bimodal distribution) or approximate mutation-drift equilibrium (multimodal distribution). The sum of squared deviations (SSD) between the observed and the expected distribution and the raggedness index $\mathrm{r}$ of the observed distribution of the mis- 
match classes (Harpending, 1994) were computed as test statistics under the hypothesis of population growth. We implemented Fu's F- (Fu, 1997) and Tajima's D-tests (Tajima, 1989) of neutrality to verify excess of recent mutations as evidence of recent population expansion. Mismatch distribution analyses and neutrality statistics were performed in ARLEQUIN v.3.1 (Schneider et al., 2000).

We constructed a haplotype network based on statistical parsimony using TCS v1.21 (Clement et al., 2000). This method links haplotypes with the smaller number of differences and identifies the most probable ancestral haplotype according to coalescent theory (Castelloe and Templeton, 1994), allowing us to estimate the evolutionary relationships between the haplotypes. Nested clade analysis (NCA) was used in order to integrate the geographic distribution of the haplotypes in the analyses. The GeoDis v.2.0 program (Posada et al., 2000) was used to test whether genetic variability was geographically structured or not. NCA nesting design, Geodis, NCA distance measures, and their statistical significance were calculated using the ANECA v.1.2 package (Panchal, 2007). Inferences of demographic processes responsible for the observed pattern of haplotype associations were performed based on the updated version of inference key according to Templeton (2004).

\section{RESULTS}

\section{Sequence diversity and genetic structure}

A total of 582-bp COI sequences were generated on each of the 93 individuals studied, revealing 71 unique haplotypes and 29 segregating sites. Data alignment was unambiguous and translation of the nucleotide sequences into amino acids revealed no stop codons, suggesting that all sequences are functional mitochondrial protein-coding sequences. We found a remarkable amount of unique haplotypes (76\%), resulting in high values of haplotype diversity estimated from both populations. On the other hand, individuals of different Tripuí sampling sites with identical haplotypes were found, but no shared haplotype was found among individuals of Tripuí and Itacolomi populations (Table 1). The nucleotide diversity within the Tripuí population was almost twice that within the Itacolomi population (Table 2). Conversely, the Watterson estimation of the theta parameter, which is based on the number of segregating sites, was higher in Itacolomi (5.65) than in Tripuí (3.87).

Table 1. Summary of Epiperipatus acacioi sampling and haplotype distribution.

\begin{tabular}{|c|c|c|c|c|}
\hline Population/sampling site & Code & UTM coordinates & Haplotypes & $\mathrm{N}$ \\
\hline \multicolumn{5}{|l|}{ Tripuí population (TRI) } \\
\hline Site 1 & $\mathrm{~T} 1$ & $-203836 /-435525$ & $\mathrm{H} 1, \mathrm{H} 2, \mathrm{H} 3, \mathrm{H} 4, \mathrm{H} 5, \mathrm{H} 6, \mathrm{H} 7$ & 8 \\
\hline Site 2 & $\mathrm{~T} 2$ & $-203826 /-435509$ & $\begin{array}{l}\text { H8, H9, H10, H11, H12, H13, H14, H15, H16, H17, H18, } \\
\text { H19, H20, H21, H22(4), H23 }\end{array}$ & 19 \\
\hline Site 3 & $\mathrm{~T} 3$ & $-203828 /-435519$ & H27, H33, H34, H35, H36, H37 & 6 \\
\hline Site 4 & $\mathrm{~T} 4$ & $-203850 /-435459$ & $\mathrm{H} 24, \mathrm{H} 25, \mathrm{H} 26, \mathrm{H} 27(2), \mathrm{H} 28, \mathrm{H} 29, \mathrm{H} 30, \mathrm{H} 31, \mathrm{H} 32$ & 10 \\
\hline Site 5 & T5 & $-203842 /-435452$ & H9, H20(3), H38(6), H39, H40, H41, H42, H43, H44, H45 & 17 \\
\hline Site 6 & T6 & $-203834 /-435452$ & $\mathrm{H} 46, \mathrm{H} 47(2), \mathrm{H} 48(2), \mathrm{H} 49, \mathrm{H} 50, \mathrm{H} 51, \mathrm{H} 52, \mathrm{H} 53, \mathrm{H} 54, \mathrm{H} 55$ & 12 \\
\hline Site 7 & $\mathrm{~T} 7$ & $-203879 /-435427$ & $\mathrm{H} 20, \mathrm{H} 38, \mathrm{H} 56, \mathrm{H} 57$ & 4 \\
\hline Site 8 & $\mathrm{~T} 8$ & $-203840 /-435396$ & $\mathrm{H} 9, \mathrm{H} 14, \mathrm{H} 22, \mathrm{H} 58$ & 4 \\
\hline \multicolumn{5}{|l|}{ Itacolomi population (ITA) } \\
\hline Site 1 & I1 & $-204356 /-435115$ & H59, H60, H61, H62, H63, H64, H65, H66 & 8 \\
\hline Site 2 & $\mathrm{I} 2$ & -204324 / - 435122 & H67, H68, H69, H70, H71 & 5 \\
\hline
\end{tabular}


Table 2. Summary statistics for genetic variation from Epiperipatus acacioi populations.

\begin{tabular}{lllllcccc}
\hline Population & $\mathrm{N}$ & $\mathrm{H}$ & $\mathrm{S}$ & $\mathrm{Hd}$ & $\pi(\%)$ & $\theta_{\mathrm{S}}$ & $\mathrm{F}$ & $\mathrm{D}$ \\
\hline Tripuí & 80 & 58 & 28 & 0.984 & 1.76 & $3.867 \pm 1.926$ & $-24.51(\mathrm{P}<0.001)$ & $2.50(\mathrm{P}=0.994)$ \\
Itacolomi & 13 & 13 & 12 & 1 & 0.97 & $5.653 \pm 1.830$ & $-8.64(\mathrm{P}<0.001)$ & $1.90(\mathrm{P}=0.98)$ \\
\hline
\end{tabular}

$\mathrm{N}=$ number of samples; $\mathrm{H}=$ number of haplotypes; $\mathrm{S}=$ number of polymorphic sites; $\mathrm{Hd}=$ haplotype diversity; $\pi=$ nucleotide diversity; $\theta_{\mathrm{s}}=$ theta population parameter from Waterson; $\mathrm{F}=$ Fu's F-statistics; $\mathrm{D}=$ Tajima's D-statistics.

The exact test of sample differentiation $(\mathrm{P}=0.0008)$ and pairwise $F_{\mathrm{ST}}$ analyses revealed that Tripuí and Itacolomi samples were different $\left(F_{\mathrm{ST}}=0.214, \mathrm{P}<0.00001\right)$. Considering the sampling sites within the populations, no significant difference was found between the samples from the two Itacolomi sites (I1 and I2). Considering the Tripuí samples, low genetic differentiation was observed among the sites, with most of the pairwise $F_{\text {ST }}$ estimates being nonsignificant (19 of 28 comparisons). The exception was the T8 sample, which was significantly differentiated from all the other Tripuí samples (Table 3). AMOVA showed significant genetic structuring among $E$. acacioi samples $\left(F_{\mathrm{ST}}=0.27, \mathrm{P}<0.00001\right)$, with $72.86 \%$ of the total genetic variance explained by variation within the populations (Tripuí and Itacolomi), $8 \%$ among groups within the populations (sampling sites), while differences between the two populations contributed with $19.14 \%$ to the total genetic variance (Table 4 ).

\begin{tabular}{|c|c|c|c|c|c|c|c|c|c|c|}
\hline & $\mathrm{T} 1$ & $\mathrm{~T} 2$ & $\mathrm{~T} 3$ & $\mathrm{~T} 4$ & $\mathrm{~T} 5$ & T6 & $\mathrm{T} 7$ & $\mathrm{~T} 8$ & I1 & I2 \\
\hline \multicolumn{11}{|c|}{ Tripuí samples } \\
\hline $\mathrm{T} 1$ & - & 61.53 & 5.52 & $\infty$ & 4.59 & 7.20 & 19.76 & 1.11 & 1.26 & 1.49 \\
\hline T2 & 0.008 & - & 7.12 & $\infty$ & 3.71 & 7.82 & 14.36 & 2.46 & 1.74 & 1.55 \\
\hline T3 & 0.083 & 0.066 & - & $\infty$ & 6.05 & 2.81 & 41.69 & 1.31 & 1.41 & 1.48 \\
\hline $\mathrm{T} 4$ & -0.023 & -0.011 & -0.054 & - & 9.73 & 4.12 & $\infty$ & 1.00 & 1.34 & 1.48 \\
\hline T5 & 0.098 & $0.119^{*}$ & 0.076 & 0.049 & - & 2.23 & $\infty$ & 0.87 & 1.39 & 1.43 \\
\hline T6 & 0.065 & 0.060 & $0.151^{*}$ & 0.108 & $0.183^{*}$ & - & 3.58 & 1.24 & 1.15 & 1.14 \\
\hline $\mathrm{T} 7$ & 0.025 & 0.034 & 0.012 & -0.038 & -0.092 & 0.123 & - & 0.49 & 1.27 & 1.43 \\
\hline $\mathrm{T} 8$ & $0.311^{*}$ & 0.169 & $0.276^{*}$ & $0.333^{*}$ & $0.366^{*}$ & $0.288^{*}$ & $0.507 *$ & - & 0.39 & 0.40 \\
\hline \multicolumn{11}{|c|}{ Itacolomi samples } \\
\hline I1 & $0.284 *$ & $0.223^{*}$ & $0.262 *$ & $0.272 *$ & $0.265^{*}$ & $0.304 *$ & $0.282 *$ & $0.564 *$ & - & $\infty$ \\
\hline $\mathrm{I} 2$ & $0.251 *$ & $0.243^{*}$ & $0.253^{*}$ & $0.252 *$ & $0.259^{*}$ & $0.305^{*}$ & $0.260^{*}$ & $0.553^{*}$ & -0.050 & - \\
\hline
\end{tabular}

$* F_{\mathrm{ST}}$ values are significant $(\mathrm{P}<0.05$, with 10,000 permutations $)$.

Table 4. Results of analyses of molecular variance (AMOVA) for the Epiperipatus acacioi COI data.
\begin{tabular}{lcccc}
\hline Source of variation & Variance components & \% of variation & Fixation indices & P \\
\hline Among populations & 1.16138 & 19.14 & $F_{\mathrm{CT}}=0.1914$ & $\mathrm{P}=0.0013$ \\
Among sites within populations & 0.48549 & 7.00 & $F_{\mathrm{SC}}=0.0989$ & $\mathrm{P}=0.0007$ \\
Within populations & 4.42060 & 72.86 & $F_{\mathrm{ST}}=0.2714$ & $\mathrm{P}<0.0001$ \\
Total & 6.06747 & & \\
\hline
\end{tabular}

\section{Demographic inferences}

Fu's F-statistics were significant for both populations (Table 2). These results rejected the null hypothesis of constant population size and suggest an excess of recent/rare mutations, which 
is consistent with a rapid population expansion. This pattern corroborated by mismatch analysis (Figure 2), which revealed no significant deviation from the null hypothesis of population expansion for both populations (Tripuí $\mathrm{P}_{\mathrm{SSD}}=0.75$ and Itacolomi $\mathrm{P}_{\mathrm{SSD}}=0.77$ ), and the raggedness index confirmed the unimodal distribution characteristic of population expansion (Tripuí $\mathrm{P}_{\mathrm{r}}=0.94$ and Itacolomi $\left.\mathrm{P}_{\mathrm{r}}=0.85\right)$. Tajima's D-tests were nonsignificant for both populations.

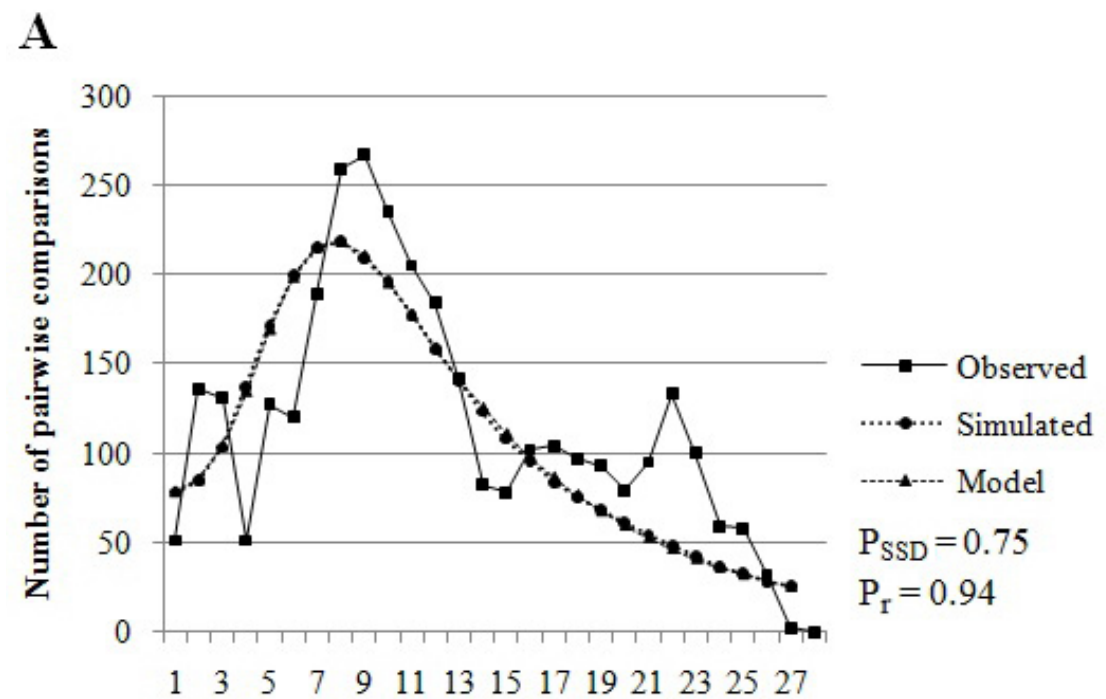

Pairwise difference

B

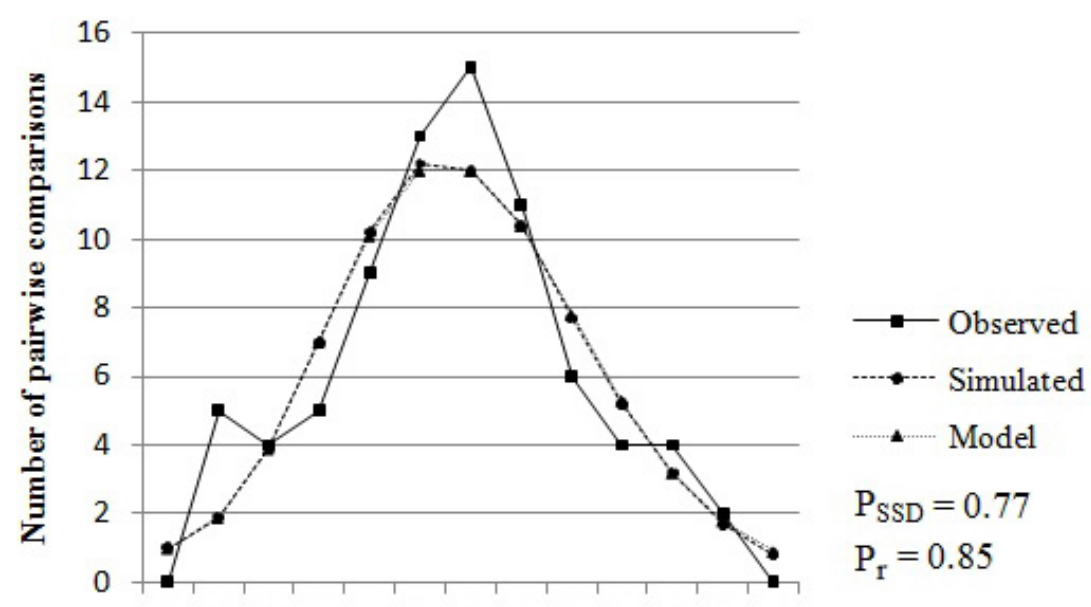

$\begin{array}{lllllllllllll}1 & 2 & 3 & 4 & 5 & 6 & 7 & 8 & 9 & 10 & 11 & 12 & 13\end{array}$

Pairwise difference

Figure 2. Mismatch distributions for A. Tripuí and B. Itacolomi population haplotypes. $\mathrm{P}_{\mathrm{SSD}}$ and $\mathrm{P}_{\mathrm{r}}$ values represent $P$ values of sum of squared deviations (SSD) and raggedness index tests. 
The haplotype network produced by TCS for E. acacioi samples showed a maximum of 9 mutational steps between haplotypes (see Figure 3). The parsimony network presented 9 ambiguity loops, which were solved following the rules suggested by Crandall and Templeton (1993) based on coalescent theory. The most common haplotype, H38, was estimated as the most probable ancestral haplotype. This haplotype was detected in four Tripuí. All Itacolomi samples presented private haplotypes and they were connected to Tripuí samples through two mutational steps (H10-H63). Nested clade analyses failed to reject the hypotheses of no association between haplotype variation and geography for all four nesting levels (data not shown). The NCA results were consistent with the Mantel test results, in which no association between genetic and geographic variation was verified.

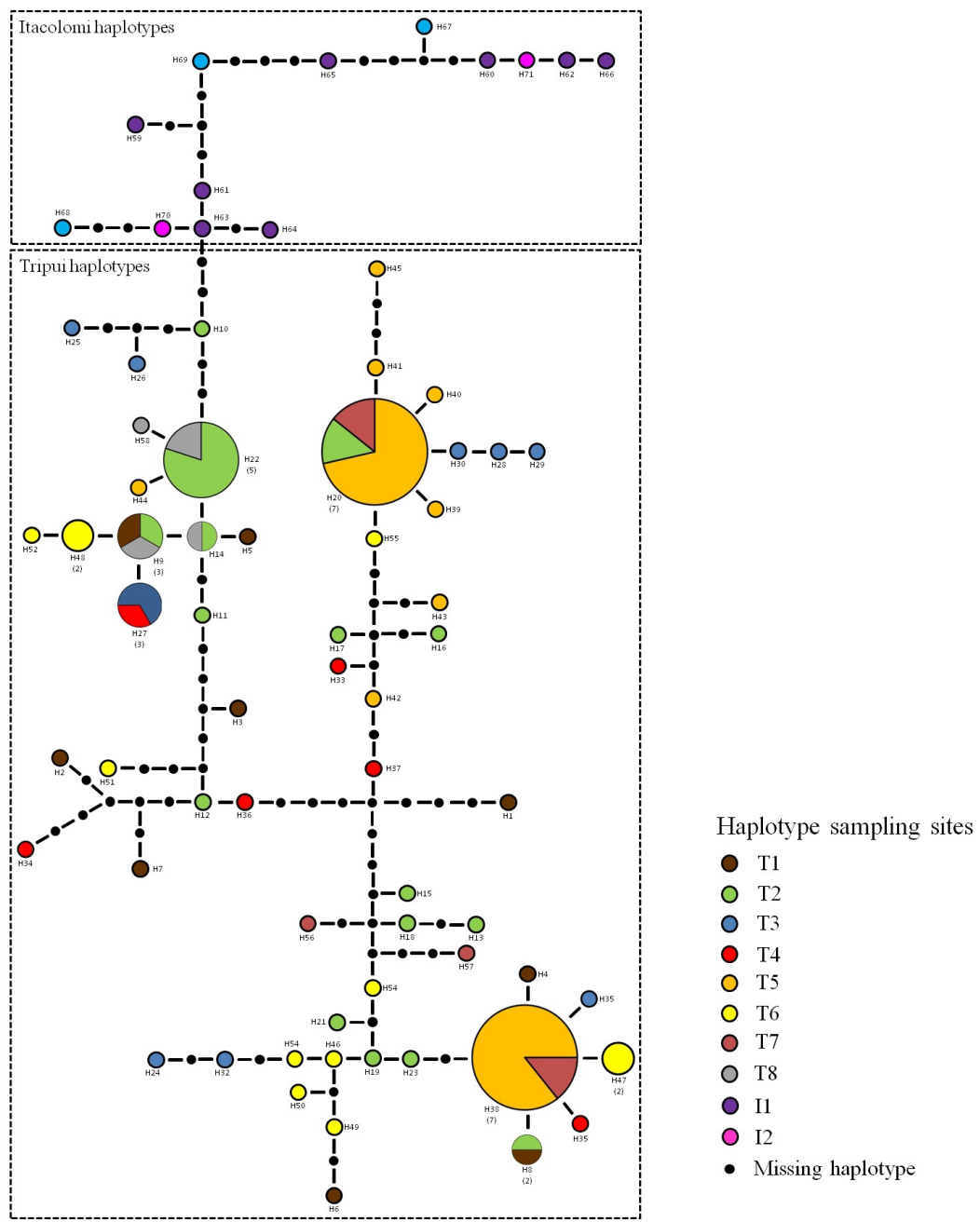

Figure 3. Network of Epiperipatus acacioi haplotypes using statistical parsimony. Circles represent haplotypes with the area of the circle proportional to the frequency of the haplotype. Colors represent the sampling sites. Small black circles indicate substitutions (missing haplotypes). 


\section{DISCUSSION}

This is the first study on Onychophora populations addressing aspects of the structuring of genetic variation, although this type of study is important for understanding the demographic history of the species and evaluating their threat levels. The analyses of nucleotide and haplotype diversity revealed that populations of E. acacioi present higher levels of genetic diversity when compared with populations of other invertebrate endangered species (Moya et al., 2004; Anderson, 2007; Strasser and Barber, 2009). Due to the lack of data about mutation rates $(\mu)$ for the COI gene in Onychophora, the population sizes could not be estimated. Nevertheless, the high values of $\theta_{\mathrm{S}}$ estimated for the $E$. acacioi populations suggest that their population sizes are not as limited as it was expected based on the low biotic potential of Onychophora.

In terrestrial habitats, small animals without wings can be expected to have lower levels of gene flow and higher levels of population differentiation (Irwin, 2002). However, this pattern was not observed for E. acacioi populations, which showed significant levels of gene flow between sampling sites along their range. Only the T8 samples showed significant genetic differentiation when compared with the other Tripuí sampling sites, suggesting the existence of some genetic barrier isolating this site and leading to genetic divergence. AMOVA revealed that most genetic variation is distributed among individuals within the populations $(72.9 \%)$, reinforcing the evidence of a low structure between occurrence sites within the populations. We also observed no evidence of isolation by distance (Mantel test and NCA results), suggesting that the potential for dispersal of E. acacioi may also be greater than expected based on their cryptic behavior and its reduced vagility. In addition, both the analysis of mismatch and neutrality tests indicated a previous expansion of the populations of E. acacioi suggesting that they went through historical bottleneck events or that they experienced a period of stability followed by recent expansion.

Our results suggest that environmental degradation resulting in the creation of small isolated fragments of high humidity surrounded by dry areas, and proposed by Newlands and Ruhberg (1978) as a limiting factor of dispersal for Onychophora, caused no apparent effects on the structuring of genetic variation of mitochondrial DNA, in Tripuí and Itacolomi populations. However, due to the limitation of mitochondrial markers for estimating genetic structure of recent events, we suggest that further studies using molecular markers with suitable evolutionary rates (such as microsatellites or AFLPs) be implemented in order to assess the effect of recent habitat disturbances on the genetic variation of $E$. acacioi populations.

Although the discovery of specimens of E. acacioi at Itacolomi State Park has expanded its known distribution, recent studies have suggested that specimens found in two other localities (Peti Reserve and Ibitipoca State Park) do not correspond to E. acacioi, restricting its distribution to the area sampled in this study (Oliveira et al., 2010; Lacorte et al., 2011). Our findings revealed that, despite the small geographical distance between the two areas, two distinct populations can be recognized, each one with exclusive haplotypes. Our results emphasize that the Itacolomi population needs conservation efforts equivalent to those received by the Tripuí population over the last fifty years. Moreover, the expansion of the known range of E. acacioi suggests that there might be undetected populations in adjacent areas, which are not legally preserved and are under increased risk of extinction, especially due to the expansion of urban areas and mining activities. 


\section{CONCLUSIONS}

The estimates of genetic diversity obtained from the sequences of E. acacioi samples indicated that there is considerable variability within the populations, even with the recent occurrence of environmental disturbances in E. acacioi habitats. Our findings revealed little genetic differentiation among samples from different sampling sites, but the samples from Tripuí and Itacolomi showed significant levels of divergence and should be considered two distinct populations. We found evidence of recent population expansion processes for both populations, possibly related to historical bottleneck events or a period of stability followed by recent expansion.

\section{ACKNOWLEDGMENTS}

We are grateful to the Instituto Estadual de Florestas de Minas Gerais (IEF-MG) for permission to collect and help with the collection of samples. Research supported by Fundação de Amparo à Pesquisa de Minas Gerais (FAPEMIG); Conselho Nacional de Desenvolvimento Científico e Tecnológico (CNPq; \#290029/2010-4) to I.S. Oliveira and Coordenação de Aperfeiçoamento de Pessoal de Nível Superior (CAPES) to G.A. Lacorte.

\section{REFERENCES}

Anderson FE (2007). Population genetics of the carinate pillsnail, Euchemotrema hubrichti: genetic structure on a small spatial scale. Conserv. Genet. 8: 965-975.

Bohonak AJ (1999). Dispersal, gene flow, and population structure. Q. Rev. Biol. 74: 21-45.

Boore JL, Collins TM, Stanton D, Daehler LL, et al. (1995). Deducing the pattern of arthropod phylogeny from mitochondrial DNA rearrangements. Nature 376: 163-165.

Braband A, Cameron SL, Podsiadlowski L, Daniels SR, et al. (2010a). The mitochondrial genome of the onychophoran Opisthopatus cinctipes (Peripatopsidae) reflects the ancestral mitochondrial gene arrangement of Panarthropoda and Ecdysozoa. Mol. Phylogenet. Evol. 57: 285-292.

Braband A, Podsiadlowski L, Cameron SL, Daniels S, et al. (2010b). Extensive duplication events account for multiple control regions and pseudo-genes in the mitochondrial genome of the velvet worm Metaperipatus inae (Onychophora, Peripatopsidae). Mol. Phylogenet. Evol. 57: 293-300.

Campiglia S and Lavallard R (1973). Contribution a la biologie de Peripatus acacioi Marcus et Marcus. II. Variations du poids des animaux em fonction du sexe et du nombre des lobopodes. Bol. Zool. Biol. Mar. 30: 499-502.

Castelloe J and Templeton AR (1994). Root probabilities for intraspecific gene trees under neutral coalescent theory. Mol. Phylogenet. Evol. 3: 102-113.

Clement M, Posada D and Crandall KA (2000). TCS: a computer program to estimate gene genealogies. Mol. Ecol. 9: 1657-1659.

Conner JK and Hartl DL (2004). A Primer of Ecological Genetics. Sinauer Associates, Sunderland.

Crandall KA and Templeton AR (1993). Empirical tests of some predictions from coalescent theory with applications to intraspecific phylogeny reconstruction. Genetics 134: 959-969.

Ewing B and Green P (1998). Base-calling of automated sequencer traces using phred. II. Error probabilities. Genome Res. 8: 186-194.

Ewing B, Hillier L, Wendl MC and Green P (1998). Base-calling of automated sequencer traces using phred. I. Accuracy assessment. Genome Res. 8: 175-185.

$\mathrm{Fu}$ YX (1997). Statistical tests of neutrality of mutations against population growth, hitchhiking and background selection. Genetics 147: 915-925.

Gordon D, Abajian C and Green P (1998). Consed: a graphical tool for sequence finishing. Genome Res. 8: 195-202.

Green P (1994). Phrap. Available at [http://www.genome.washington.edu/UWGC/ analysistools/phrap.htm]. Accessed January 10, 2009.

Harpending HC (1994). Signature of ancient population growth in a low-resolution mitochondrial DNA mismatch 
distribution. Hum. Biol. 66: 591-600.

Irwin DE (2002). Phylogeographic breaks without geographic barriers to gene flow. Evolution 56: 2383-2394.

Lacorte GA, Oliveira IS and Fonseca CG (2011). Phylogenetic relationships among the Epiperipatus lineages (Onychophora: Peripatidae) from the Minas Gerais State, Brazil. Zootaxa 2755: 57-65.

Lavallard R and Campiglia S (1973). Contribution à la Biologie de Peripatus acacioi Marcus et Marcus I. Pourcentage des sexes et variations du nombre des lobopods dans un échantillonnage de plusieurs centaines d'individus. Bol. Zool. Biol. Mar. 30: 483-498.

Lavallard R and Campiglia S (1975a). Contribution à la Biologies de Peripatus acacioi Marcus et Marcus (Onychophore). IV. Elevage au laboratoir. Cien. Cult. 27: 549-556.

Lavallard R and Campiglia S (1975b). Contribution à la Biologie de Peripatus acaioi Marcus et Marcus (Onychophore). V. Etude des Naissances dans un Elevage de laboratoire. Zool. Anz. Jena. 195: 338-350.

Lewinsohn TM, Lucci FAV and Inacio PP (2005). Conservation of terrestrial invertebrates and their habitats in Brazil. Conserv. Biol. 19: 640-645.

Librado P and Rozas J (2009). DnaSP v5: a software for comprehensive analysis of DNA polymorphism data. Bioinformatics 25: 1451-1452.

Marcus E and Marcus E (1955). A new Peripatus from Minas Gerais, Brazil. An. Acad. Bras. Cienc. 27: 189-193.

Miller MP (2005). Alleles in space (AIS): computer software for the joint analysis of interindividual spatial and genetic information. J. Hered. 96: 722-724.

Monge-Nájera J (1995). Phylogeny, biogeography and reproductive trends in the Onychophora. Zool. J. Linn. Soc. 114: 21-60.

Moya O, Contreras-Diaz HG, Oromi P and Juan C (2004). Genetic structure, phylogeography and demography of two ground-beetle species endemic to the Tenerife laurel forest (Canary Islands). Mol. Ecol. 13: 3153-3167.

New TR (1995). Onychophora in invertebrate conservation: priorities, practice and prospects. Zool. J. Linn. Soc. 114: 77-89.

Newlands G and Ruhberg H (1978). Onychophora. In: Biogeography and Ecology of South Africa (Werger JMA, ed.). The Hague, Junk, 679-684.

Oliveira IS, Wieloch AH and Mayer G (2010). Revised taxonomy and redescription of two species of the Peripatidae (Onychophora) from Brazil: a step towards consistent terminology of morphological characters. Zootaxa 2493: 16-34.

Panchal M (2007). The automation of nested clade phylogeographic analysis. Bioinformatics 23: 509-510.

Pedralli G, Freitas VLO, Meyer ST, Teixeira MCB, et al. (1997). Levantamento florístico na Estação Ecológica do Tripuí, Ouro Preto, MG. Acta Bot. Bras. 11: 191-213.

Posada D, Crandall KA and Templeton AR (2000). GeoDis: a program for the cladistic nested analysis of the geographical distribution of genetic haplotypes. Mol. Ecol. 9: 487-488.

Raymond M and Rousset F (1995). An exact test for population differentiation. Evolution 49: 1280-1283.

Reed DH and Frankham R (2003). Correlation between fitness and genetic diversity. Conserv. Biol. 17: 230-237.

Sambrook J and Russell DW (2001). Molecular Cloning: A Laboratory Manual. CHSL Press, New York.

Schneider S, Roessli D and Excoffier L (2000). ARLEQUIN Ver 3.01: A Software for Population Genetic Data Analysis. Genetics and Biometry Laboratory, University of Geneva, Switzerland.

Strasser CA and Barber PH (2009). Limited genetic variation and structure in softshell clams (Mya arenaria) across their native and introduced range. Conserv. Genet. 10: 803-814.

Tait NN and Briscoe DA (1995). Genetic differentiation within New Zealand Onychophora and their relationships to the Australian fauna. Zool. J. Linn. Soc. 114: 103-113.

Tajima F (1989). Statistical method for testing the neutral mutation hypothesis by DNA polymorphism. Genetics 123 : 585-595.

Tamura K, Dudley J, Nei M and Kumar S (2007). MEGA4: Molecular Evolutionary Genetics Analysis (MEGA) software version 4.0. Mol. Biol. Evol. 24: 1596-1599.

Templeton AR (2004). Statistical phylogeography: methods of evaluating and minimizing inference errors. Mol. Ecol. 13: 789-809.

Wells SM, Pyle RM and Collins NM (1983). The IUCN Invertebrate Red Book Data. IUCN, Cambridge. 